\title{
New Market, New Challenge, New Opportunity (1) -Overview of China rural healthcare \& Design methodology
}

\author{
Jiang Jiehui and Prabhu Kandachar \\ Faculty of Industrial Design Engineering, Delft University of Technology, the Netherlands
}

\begin{abstract}
China has a largest population in the world (1.3Billion) and 0.9 Billion is rural population. Most of rural people earn less than US\$3/day, and they are called "Base of the economic pyramid (BoP)". Compared with high level market, BoP is a new market, which means a low individual profit, but a large population. This paper discusses the healthcare issues in rural China (BoP) and study their healthcare needs through field study and case studies. This research is carried out within the framework of "Design for Sustainability at Base-of-the-Pyramid (BoP)" programme of the School of Industrial Design Engineering at Delft University of Technology. And the aim of this research is to provide a low cost advanced healthcare product design, which will meet poor's needs and create a business case for commercial partners.

Key words - Rural healthcare, Base of the pyramid (BoP), Design for Sustainability
\end{abstract}

\section{INTRODUCTION}

\section{A. Rural China}

$\mathrm{C}$ Thina has a largest population in the world (1.3 Billion) and 0.9 Billion is rural population [1].They are composed of 0.75 Billion rural people who live in rural and 0.15 Billion who live in urban as migrant workers [2]. Although their average income increases every year to about 4000RMB/year (US\$1.4/day) at the end of 2006 [1], the income gap between rural and urban is becoming large year by year [3].

According to the World Bank (2005), there are 4 billion people living on an income less than US\$3 per day and 1 billion living less than even US $\$ 1$ per day. This part of the population is often called "Base-of-the-Pyramid" (BoP), referred by Prahalad and Hart $[4,5]$. And so more than $95 \%$ china rural belongs to BoP under this standard [1].

Similar with BoP population in other countries, there are many market opportunities in rural China such as energy, communication and healthcare [5].

\section{B. Healthcare design for rural China}

Currently, most of the entrepreneurs, professional designers and design institutes are targeting the end-users in advanced markets as this group has a higher purchasing power of average more than US $\$ 10,000$ per year. C.K Prahalad and Stuart Hart's $[4,5]$ work in this area suggests that there is a

Jiang Jiehui is a PhD candidate in Department of Design Engineering, Faculty of Industrial Design Engineering (IDE), Delft University of Technology, Netherlands. Address: Room 3A.42, Landbergstraat 15, 2628 CE Delft The Netherlands Phone:+31 J.Jiang@tudelft.nl

Prof. Dr. .P. V. Kandachar is also with this Faculty of Industrial Design Engineering. He is also Chairman of the Department of Design Engineering.. E-mail: P.V.Kandachar@tudelft.nl . fortune to be made for entrepreneurs in BoP initiatives, while at the same time great opportunities for the world's poor to escape from poverty. Prahalad's book 'The Fortune at the Bottom of the Pyramid' [5] proposes a framework for the active engagement of the private sector and suggests a basis for a profitable win-win engagement. He argues that all that is stopping business from designing products and services to meet the needs of the world's poor, and then efficiently manufacturing and distributing them is human ingenuity innovation. The topic has unleashed an extensive and generally enthusiastic response from academics, businesses, NGOs and governments.

Recently, some Multi National Companies (MNC) such as HP, Intel, Philips and Microsoft have been aware of the design opportunities of this market, as well as some design institutes such as Delft University of Technology (DUT), Illinois Institute of Technology (IIT), Berkley and Standford which are partnering with MNCs for BoP design.

\section{NEW MARKET: HeALTHCARE IN RURAL CHINA}

Different from some developed industrial countries, Chinese civilization and development is based on agriculture development. Chinese government has paid a lot focus on improving rural economics. From 1978 to 1998, China rural economic has experienced three "Fast golden development period" [6], the poverty percent of rural population decreased from $30.7 \%$ to $4.6 \%$ [7], rural China has solved basic living needs like fighting hungry. From 1998, a new rural golden development period has started, which is named "New rural, new construction". A new Chinese rural area revolution proposal has been picked up, that is composed with economic revolution, healthcare revolution and culture revolution [8]. Even now, healthcare issues for rural areas are still a hottest topic in China, which are mentioned many times in Chinese Government Conferences. [9]

With the income increasing of rural areas, rural population has started to pay more attentions on their health situation and their personal health expenditure is growing fast in this decade. (Figure1)

In the figure, both urban and rural health expenditure has increased about 6 times from 1978 to 1998, but these data won't make sense for us due to Chinese health system has experienced revolution from plan reform to market reform in this period and the percent of government health expenditure has decreased from $36.2 \%$ to $15.5 \%$ [10]. After 2000, the increasing rate is steady and keeps in $8-10 \% / y e a r, ~(2005$ is special because of SARS, and Chinese government added expenditure for public health affair) which indicates per capita health expenditure in rural may arrive 480yuan/year in 2010. 
Figure 2 gives another description, which shows the health expenditure rate (HER) of household consumption expenditure. HER = per capita health expenditure/ per household consumption expenditure.

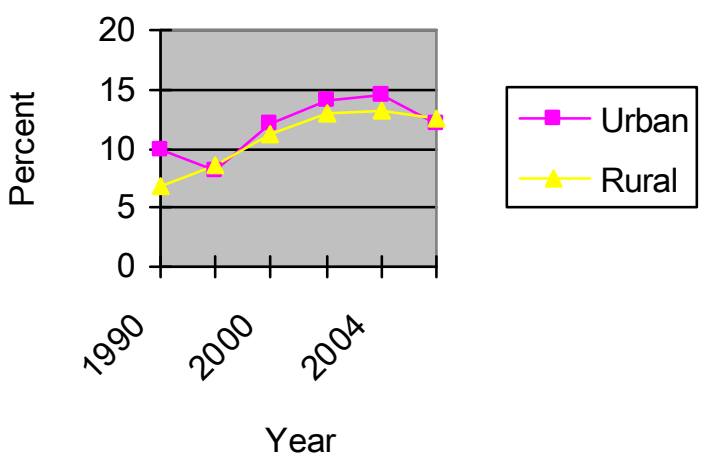

Figure 2: Rate of health expenditure in consumption expenditure Source: China Ministry of health 2007 and China national bureau of Statistic 2007

Per Capita Health Expenditure

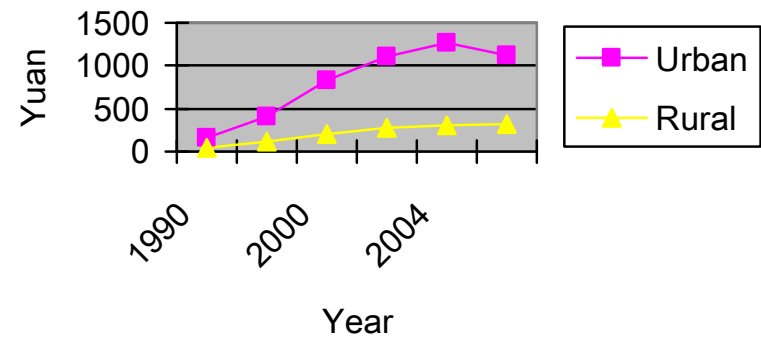

Figure 1: Per Capita Health Expenditure in China urban and rural Source: China Ministry of health 2007

This figure shows the market potential of rural healthcare. Compared with urban people, the rural HER is increasing fast, which means rural people's health care needs are more urgent. And the fact is that every rural household has paid more and more expense on health care. If fast development of Chinese economics is considered, the increase is abundant.

However, the increase is negative sometimes. Rural people have to pay the same expense if they want to share same health service with urban people. As a result, challenges are still there if someone would like to emerge this market.

\section{NeW Challenge: PRIMARY HEALTH CARE IS THE KEY TO OPEN THIS MARKET?}

To suit the economic development process of rural China, Chinese rural health system has also experienced two main revaluations. The first is in the middle 1960s. To improve the rural health situation, Chairman Mao made an important direction "China should emphasis rural healthcare". And as a result, a lot of workers and farmers in rural areas had changed their careers into medical field to be doctors. Most of them (about 1.5 million at that time) didn't get any special medical education, and just through studying from books by themselves, start to work as a doctor in villages. They are described as: "In rural area, it's easy to find some doctors in the farm. Same with other farmers, they are walking in the farm without shoes and doing farm works."[11] In 1968, they are identified "Barefoot Doctors" formally by Chinese government. The second revolution happened in the late of 1970s, the transformation from plan economics to market economics caused the collapse of the widely acclaimed rural cooperative medical system in China. Unfortunately, the revolution resulted in a lot of travails such as a decreased supply of rural health workers, increased burden of illnesses, disintegration of the three tier medical system, reduced primary health care, and an increased demand for hospital medical services [12].

To improve rural health condition, from 2005, a new rural cooperative medical system has been set up. Three tier hospital systems are remained and primary health care is increased. Figure 3 shows three tier hospital system and rural details are described in it.

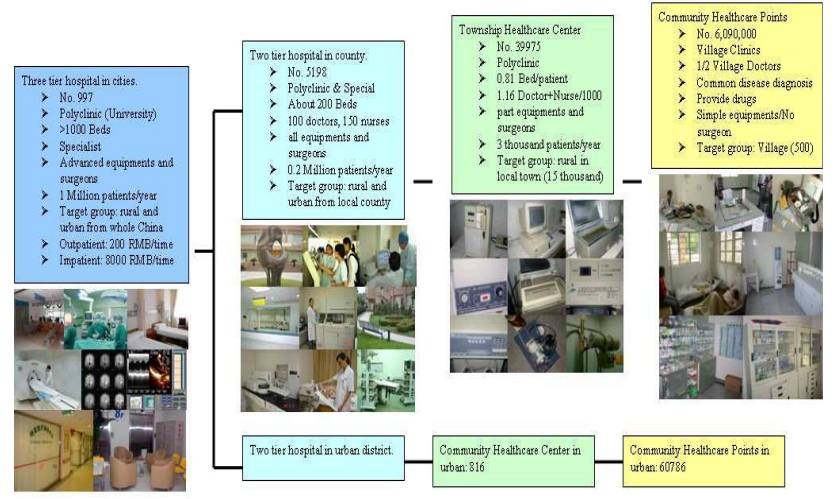

Figure 3: China three tier hospital system

Source: Shanghai Ruijin hospital, Shanghai Jinshan hospital and field studies in rural Shanghai

In this system, only urban area has three tier hospitals. Three tier hospitals, usually supposed by local medical University, have advanced equipments and specialists. For most rural people, it's not possible to go to three tier hospital unless a unique disease. Rural people will go to two tier hospital if they get a serious disease although it's a long distance. Two tier hospitals almost provide all kinds of diagnosis and surgeons but the qualities are a little worse than three tier hospitals.

Township Healthcare Center (THC) and Village Healthcare Point (VHP) belong to primary health care. And they are serving for local rural especially. THC provides parts of diagnosis, treatment and simple surgeons but the equipments are not advanced as showed in figure 3 . VHP is the fundamental health care organization in rural area. Every VHP has one or two Village doctors and is composed of a consulting room, a transfusion and observation room, a treatment Room, a drug store and an education room sometimes.

Compared with high tier hospitals, primary health care seems a larger potential on rural health care design due to: 
1. Large target group: China has 39,975 THCs and $6,090,000$ VHPs and they will care at least 0.6 Billion rural people directly. The user group is attractive enough.

2. Gaps between health care needs and current situation: Current health resources can't meet all health needs. Two big problems are existing: the first one is the knowledge of village doctors, most of current village doctors are previous barefoot doctor from Mao period without any formal medical education and average education in THC is secondary technical school (The same with high school).[9] The second one is shortage of medical resources, many medical services are insufficient based on our observation and perception of THCs and VHPs and through conversation and interaction with local patients. This research is finished in 2006 by a combined student group of TUDelft and Shanghai University.

3. Policy of Chinese government: Chinese government will pay a policy prefer on rural primary health care. One case is that in the new rural cooperative medical insurance, the reimbursement percent of VHP will be increased into $60 \%$, THC will be $40 \%$ while $30 \%$ and $20 \%$ in high tier hospitals.[13]

Also, some previous researches will give some ideas, such as by Hart for rural design [14]:

$>$ Engage in deep listening and mutual dialogue with target group

$>$ Co-discover and co-create new product design opportunities and business models embedded in the local cultural infrastructure

$>$ Co-design and launch products that generate mutual value for all partners.

Although it has good opportunities to design for primary health care, a lot of factors should be considered before a prefect design and a successful business. So a suitable design methodology is necessary, and it will bring new opportunities on this topic.

\section{NEW OPPORTUNITY: IDE DESIGN METHODOLOGY FOR RURAL HEALTH CARE}

Based on a statistical analysis of an extensive inquiry amongst approximately 800 Chinese Migrant Workers, their healthcare needs have been identified. This analysis can be used to as an input to explore opportunities for design interventions and eventually designing products and services to address the healthcare issues of Chinese Migrant Workers.

Different with other sustainable design methodologies, the topic of "design for China rural" is not only a design for poverty but also for the environment where rural lives. As same as other BoP products, new products and services for China rural health care need to be very eco-efficient [15].

The School of Industrial Design Engineering (IDE) at Delft Technology of University (TUdelft) has been exploring this strategy since 2003 with the needs of the users as a starting point for BoP product and innovations [16-19]. Building further on this expertise, Kandachar [16-19] has observed that several innovations are taking place that need to be considered for an effective approach to serve the unmet needs of the
BoP-community. These innovations include: on user side ethnographic tools, cultural probes, business innovations such as hybrid business models, corporate responsibility, technological innovations like disruptive innovations, open source designs, etc. Other innovations at the entrepreneurial side such as microfinance, social entrepreneurship need to be considered as well. A schematic of the design process and the several innovations needed are shown in figure 4:

To achieve the innovations of society, technology and market mentioned above, a research approach is supposed in Figure 5. A total of twelve parts are being considered in this

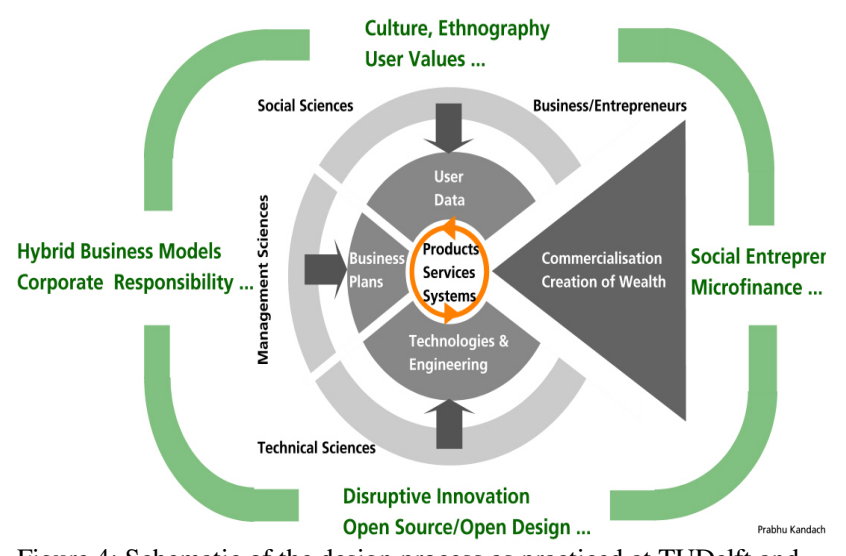

Figure 4: Schematic of the design process as practiced at TUDelft and the need for innovations at several fronts to meet the unmet needs of the BoP community.[18]

design approach, divided into three levels. And different level means different research fields for a project; the output should be a project which includes design opportunities, product design and business opportunities. (Like a triangle)

Some small circles can in the figure and they mean the process of re-design, which will help to improve the designs.

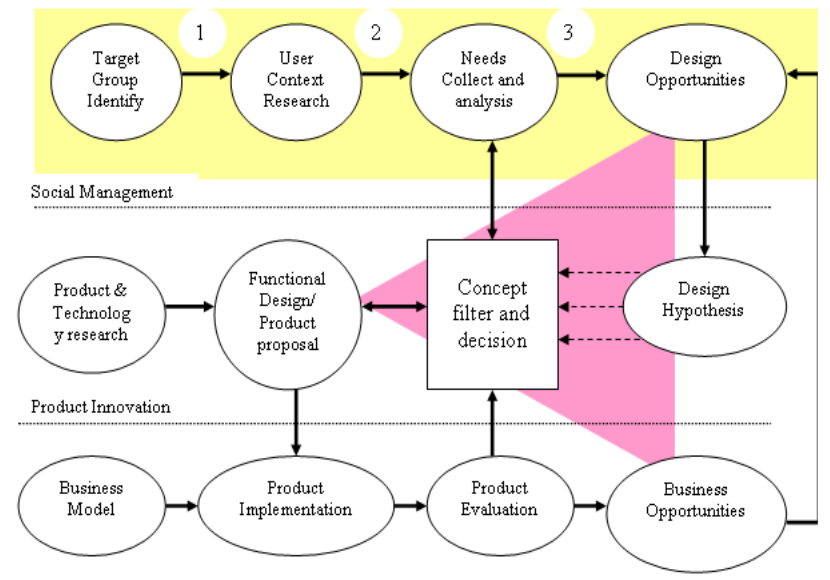

Figure 5: Design approach for China rural healthcare

"Needs-Design concept": Rural healthcare design is completely a research of "Design for needs" because the purchasing power of rural China is limited. The best way to emerging this market is need-emphasis. A product or service will be welcomed if it can solve urgent healthcare needs or some different needs at the same time. For example, a design for cancer diagnosis will be much more effective than fever diagnosis and a design for all chronic 
diseases care will be more effective than only hypertension monitoring. The feedback of needs analysis is useful to improve the concept and any design aspiration has to be tested by user needs through user studies.

$>$ "Product -Market": Different from other common consumer products, design for rural healthcare includes not only "How to sell the product/service?" but also "How to set up a successful service network?" Usually it takes a long time to let user to accept a new health care product, (It is about health and is a long process of unknown-doubt-try-use-accept-like-reply)and it is changeable due to rural population in China has health education rarely and lack of health awareness[20]. A cooperated model will be constructed and all stakeholders may take own responsibilities.

$>$ "Design-Business": Business factors should be considered in a design for rural healthcare. MNCs are usually though of as main partners and sponsors in most cases, so business will lead design sometimes such as "Design for malaria diagnosis" is more attractive than "Design for brucellosis flow assay" because China rural has a larger target for previous diagnosis.

The evaluation standard for above approach is "4 As", namely Availability, Affordability, Acceptability and Awareness. The "4 As" will be used to decide whether the design has a successful feasibility.

$>$ Availability - Unlike developed market, a product or service for China rural healthcare should affect users through different channels. One hypothesis is portable device, and it can work for China rural anytime and anywhere.

$>$ Affordability - The design for rural healthcare should be low cost and sustainable because target group is in low incomes. There is no a comparison standard for price reduction but at least 80 percent of the cost of a compared product in western is necessary.[21] The common design tool is to use advanced technologies such as Information and Communication Technology (ICT), nanotechnology (New package material) and biotechnology.

$>$ Awareness- Health awareness level of China rural should be considered before a design, and it's perfect if the design will help build awareness and education. However this is a big challenge for all stakeholders.

$>$ Acceptability-Social-culture is another important factor for designers. The designer may think of the taboo of target group, and then aesthetics.

\section{CONCLUSION \& DISCUSSION}

As a new market, Chinese rural healthcare is attractive for designers and challenges in primary health care have appeared. A new opportunity: IDE design methodology seems suitable for rural healthcare and a design approach has been described.

Recently a new research project has been initiated on "The Healthcare Design for China Rural BoP" leading to $\mathrm{PhD}$ of the first author of this paper. This paper is the part of this work and the objective of this paper is to introduce rural healthcare market and design methodology. The research will start from healthcare needs in rural China and the approach will be achieved step by step.

\section{REFERENCES}

[1] National Bureau of Statistics of China, China Statistical Yearbook2007.

[2] Leslie T. Chang, Migrant worker in China, Wall Street Journal. (Eastern edition).New York, N.Y.: Nov 8, 2004. pg. A.1

[3] John Whalley Xinming Yue, Rural Income Volatility and Inequality in China, NBER working paper series, 2006, No 12779.

[4] Prahalad C.K and Hart, S.L., (2002) Strategy + Business, Issue 26, www.digitaldividend.org/pdf/bottompyramid.pdf

[5] "Fortune at the Bottom of the Pyramid, The: Eradicating Poverty Through Profits" (Publisher: Wharton School Publishing, 2005, ISBN-10: 0-13-187729-1, ISBN-13: 978-0-13-187729-0, Pages: 304)

[6] Wen Jiabao, Revoluation for rural economics, Qiu Shi(2006) Volume 18, Page 1-19

[7] Albert PARK, Sangui WANG, China's poverty statistics, China Economic Review 12 (2001) 384-398

[8] Ye Song, Theory and Practice for "Agriculture , Ruralareas and Peasantry", Xinhua Press(2003), Page 1-3

[9] Hu Jingtao. The report of 17th National Congress of Communist Party of China(2007). Beijing.

[10] Chinese Ministry of Health, Chinese health statistic digest 2007, P45-113

[11] Zhang Xin. From farmer to barefoot doctor, People Daily. 1968.

[12] [Yuan Liliu, William C, etc. Transformation of China's rural health care financing, Social Science and Medicine, Volume 41, Issue 8, October 1995, Pages 1085-1093

[13] Wang Yanzhong, The meaning of new comparative rural health insurance (in Chinese), Strategy and Management (2001), Issue 3, Page 15-24.

[14] Hart.S, Base of the pyramid protocol (2004). Cornell University

[15] Sethia,N. At the bottom of the pyramid: Responsible design for responsible business. Design Management Review(2005) 16.

[16] Kandachar, P.V. Base-of-the-Pyramid Strategies and Global Sustainability, Keynote Speech, 13th International Conference of the Greening of Industry Network[GIN], Cardiff, Wales, UK July $2-5,2006$

[17] http://www.io.tudelft.nl/live

[18] Kandachar, P.V and Halme, M., Introduction: An Exploratory Journey Towards the Research and Practice of the "Base-of-the-Pyramid", Grenner Management International, Issue 51, June 2007, p.3-17. ISSN: 0966-9671. Edited by: Prabhu Kandachar. Greenleaf Publishing, Sheffield, UK

[19] Kandachar.P.V, Designing for the Base of the Pyramid, Keynote at The 9th International Conference on Engineering and Product Design Education, Northumbria University, Newcastle upon Tyne, 13-14 September 2007, http://www.cfdr.co.uk/epde07/

[20] Dongfeng Gu, Kristi Reynolds etc, Prevalence, Awareness, Treatment, and Control of Hypertension in China. Downloaded from http://www.hyper.ahajou9r2n0als.org by on February 25, 2008

[21] Anderson, J. "A structed approach for bring mobile telecommunications to the world,s poor" The electronic journal on information systems in developing countries (2006) 27(2), Page 1-9 